\title{
REKONSTRUKSI BAHAN AJAR BERBASIS STEM UNTUK MENINGKATKAN LITERASI SAINS DAN TEKONOLOGI SISWA PADA KONSEP KEMAGNETAN
}

\author{
Rusyati $^{1)}$, Anna Permanasari ${ }^{2)}$, Didit Ardianto ${ }^{3)}$ \\ ${ }^{1)}$ Program Studi Pendidikan IPA, Universitas Pakuan \\ 2) Dosen Program Studi Pendidikan IPA, Universitas Pendidikan Indonesia \\ ${ }^{3)}$ Dosen Program Studi Pendidikan IPA, Universitas Pakuan
}

Email: anna_permanasari@upi.edu

\begin{abstract}
Abstrak: Tujuan penelitian ini adalah untuk memenuhi kebutuhan bahan ajar IPA dengan tema kontekstual agar siswa menguasai sejumlah keterampilan abad 21 . Aktivitas utama dari penelitian ini adalah merekonstruksi struktur konten pengetahuan tentang teknologi, menjadi struktur konten untuk pembelajaran dengan memperhatikan kurikulum dan perkembangan siswa. Tujuan penelitian ini adalah untuk menghasilkan bahan ajar IPA berbasis STEM untuk meningkatkan Literasi sains dan teknologi pada konsep kemagnetan. Metode penelitian ini adalah penelitian pengembangan dengan model prosedural yang diadaptasi dari model of education reconstruction (MER). Bahan ajar yang dihasilkan divalidasi oleh ahli untuk mengumpulkan informasi berkaitan dengan keakuratan konten dan kelayakan bahan ajar. Penilaian bahan ajar meliputi aspek materi, penyajian, dan Bahasa serta keterbacaan. Berdasarkan poin penilaian tersebut, diperoleh CVR rata-rata untuk bahan ajar berbasis $\mathrm{STEM}$ adalah $0,82, \mathrm{CVI}_{\mathrm{h}}>\mathrm{CVI}_{\mathrm{t}}(0.84>0.42)$. Nilai ini menandakan bahwa bahan ajar berbasis STEM yang dikembangkan layak digunakan. Rekonstruksi bahan ajar berbasis STEM dengan tema teknologi magnet dapat meningkatkan literasi sains dan teknologi ditunjukkan dengan rata rata hasil pretest sebesar 18,9\% dan rata rata hasil post test 52,5\%, dan \% N-gain 41,47\% termasuk katagori sedang.
\end{abstract}

Kata Kunci: Rekonstruksi, Bahan Ajar, STEM, Literasi Ilmiah dan Teknologi

\section{PENDAHULUAN}

Perkembangan sains dan teknologi di masyarakat yang sangat pesat merupakan tantangan bagi guru untuk menyiapkan peserta didik yang siap menghadapi tantangan abad 21. Siswa perlu dibekali dengan sejumlah keterampilan abad 21 yang diantaranya : ways of thinking tercakup berpikir kritis, pemecahan masalah dan pengambilan keputusan (i), kreativitas dan inovasi (ii), learning to learn dan metakognisi (iii). Dalam ways of working dikenalkan komunikasi dan kolaborasi, sedangkan dalam tools of working diperlukan literasi Informasi, dan literasi digital. Adapun dalam rumpun living in the world perlu dikembangkan citizen-ship-local dan global (i), life and career (ii), serta personal and social (iii). (Binkley et al., 2012). Keterampilan tersebut dapat mereka 
gunakan untuk bekal dimasa depan untuk menghadapi ketatnya persaingan dunia kerja.

Teknologi merupakan bentuk penerapan sains dalam kehidupan sehari-hari. Pemahaman terhadap teknologi merupakan salah satu keterampilan yang diperlukan di abad 21. Teknologi berkaitan dengan bagaimana orang menggunakan dan memanipulasi alam untuk kepentingan dan kemudahan kehidupan manusia. Penemuan, inovasi, dan perubahan yang bertujuan agar sesuai dengan keinginan dan kebutuhan, untuk hidup lebih lama dan lebih produktif akan menghasilkan teknologi (Wonacott, 2001).

Rekayasa teknologi sebagai wujud penerapan sains sangat ditentukan oleh kemampuan matematik dan rancang bangun, oleh karena itu beberapa penelitian telah mengembangkan pembelajaran sains berbasis STEM. Pendidikan STEM memberikan peluang kepada guru untuk memperlihatkan kepada peserta didik betapa konsep, prinsip, dan teknik dari sains, teknologi, enjiniring, dan matematika digunakan secara terintegrasi dalam pengembangan produk, proses, dan sistem yang digunakan dalam kehidupan sehari-hari mereka (Firman, H. 2015)

Pembelajaran perlu didukung oleh ketersediaan bahan ajar, begitu juga pembelajaran STEM. Berdasarkan hasil penelitian yang dilakukan Millah, E.S., et al (2012), buku ajar yang beredar sangat banyak, namun masih terdapat beberapa kekurangan salah satunya adalah buku yang dirancang belum mampu membuat siswa berpikir tingkat tinggi dalam memecahkan masalah autentik dalam kehidupan sehari hari.

Pada umumnya, bahan ajar yang ada masih belum mengintegrasikan antara sains, teknologi, enjiniring dan matematika (STEM) serta kurang mengangkat tema kontekstual pada kehidupan sehari hari. Bahan ajar IPA yang ada hanya mengajarkan konten pengetahuan secara langsung, tidak disertai metode ilmiah sehingga siswa kurang mampu menggunakan cara bagaimana mengembangkan pengetahuan sains, mengaplikasikan konsep dan metode sains.

Untuk dapat meningkatkan literasi sains dan teknologi, salah satunya diperlukan buku ajar yang membahas konsep IPA yang ada di lingkungan sekitar. Akan tetapi buku-buku yang membahas aplikasi langsung dari konsep konsep IPA, seperti buku tehnik atau buku teknologi tersebut belum tentu sesuai diterapkan kepada siswa SMP. Konsep yang diajarkan harus sesuai dengan Kompetensi inti (KI), Kompetensi Dasar (KD), dan Standar Kompetensi Lulusan (SKL) yang ditetapkan.

Konten pengetahuan tidak dapat secara langsung diajarkan oleh guru, melainkan perlu penelaahan mendalam mengenai struktur konten pengetahuan. Sebelum sebuah konten diangkat dalam pembelajaran. Diperlukan rekonstruksi konten ilmu menjadi bahan ajar untuk pembelajaran. Salah satu model untuk mempersiapkan bahan ajar adalah Model of Educational Reconstruction (MER).

Melihat permasalahan tersebut, perlu dikembangkan dan diteliti bahan ajar IPA berbasis STEM yang dikemas menarik, mudah digunakan dan dipahami, serta mengangkat tema kontekstual pada kehidupan sehari hari, dan dapat membantu siswa lebih melek sains dan teknologi. Karakteristik bahan ajar berbasis STEM pada tema teknologi kemagnetan yang direkonstruksi dari buku- 
buku teks dan artikel-artikel menjadi rumusan masalah yang akan dijawab dalam penelitian ini.

\section{METODE PENELITIAN}

Metode yang digunakan pada penelitian ini adalah metode penelitian pengembangan. Penelitian ini bertujun untuk menghasilkan produk, berupa bahan ajar berbasis STEM, yang disesuaikan dengan kebutuhan peserta didik.

Pada tahun 2008, Pusat Penelitian Kebijakan dan Inovasi Pendidikan (puslitjaknov) mengemukakan tiga komponen utama dalam penelitian pengembangan, yaitu : (1) Model pengembangan. (2) Prosedur pengembangan. (3) Ujicoba produk.

Model pengembangan memuat pedoman untuk mengembangkan produk yang akan dihasilkan. Model penelitian pengembangan yang digunakan untuk mengembangkan bahan ajar adalah Model of Educational Reconstruction (MER). Model ini memiliki tiga komponen yaitu: 1) analisis struktur konten, 2) penelitian empiris (penelitian mengajar dan belajar), dan 3) pengembangan dan evaluasi pelajaran (merancang pembelajaran) dan hubungannya yang saling berkaitan. Kaitan ketiga komponen dapat dilihat pada Gambar 1.

Ujicoba produk merupakan bagian yang penting dalam penelitian pengembangan (Puslitjaknov, 2008). Ujicoba bahan ajar dilakukan oleh 20 orang guru IPA SMP sebagai validator.

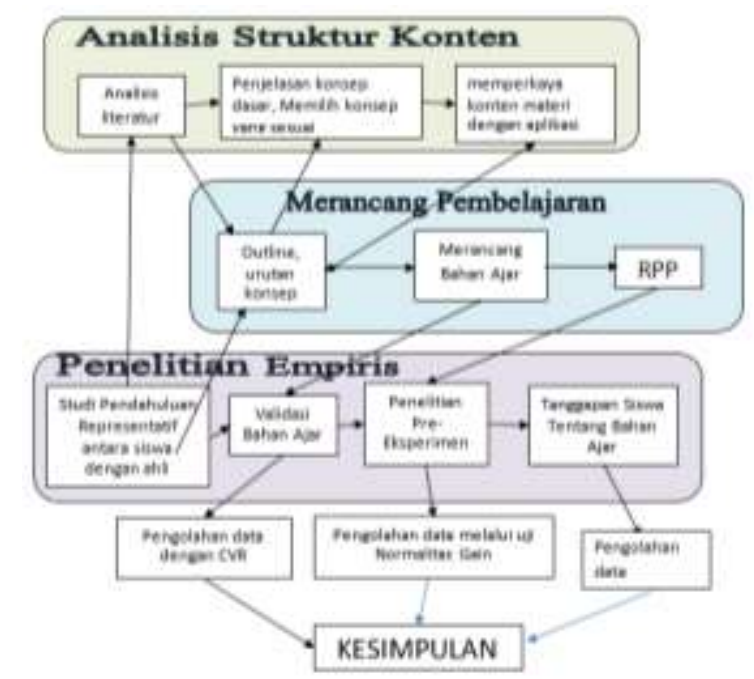

Gambar 1. Prosedur pengembangan

Subjek penelitian ini adalah siswa SMP kelas IX di salah satu sekolah kabupaten Cianjur dan 20 orang guru IPA SMP/MTs dengan pengalaman mengajar IPA yang berbeda. Tabel validasi bahan ajar digunakan sebagai instruman untuk mengetahui karakteristik bahan ajar yang direkonstruksi dengan menggunakan model MER. Instrumen untuk 
mengembangkan bahan ajar terdiri dari aspek materi, aspek penyajian, serta aspek bahasa dan keterbacaan (Ismunandar dan Permanasari, 2004).

Bahan ajar yang telah disusun, kemudian disebarkan kepada dua puluh orang guru IPA untuk divalidasi dengan menggunakan instrumen tabel validasi bahan ajar. Data tanggapan validator yang diperoleh berupa ceklist pada kolom yang tersedia, yang disertai saran. Tanggapan validator yang menyatakan "ya" bernilai satu, sedangkan tanggapan yang menyatakan "tidak" bernilai nol. Untuk menentukan apakah sebuah item dapat diterima atau ditolak, tanggapan guru-guru IPA terhadap bahan ajar, dianalisis dengan menggunakan Content Validation Ratio (CVR). Selanjutnya dilakukan perhitungan Content Validation Index (CVI) untuk menentukan nilai validasi keseluruhan tes (Lawshe, 1975). Untuk menganalisis efektivitas bahan ajar dilihat dari peningkatan literasi sains dan teknologi siswa dilakukan dengan langkah-langkah sebagai berikut: (a) Penskoran pretest dan posttest. (b) Perhitungan $N$-gain.

\section{HASIL DAN PEMBAHASAN}

\section{Prakonsepsi Siswa Tentang Kemagnetan}

Prakonsepsi adalah informasi atau ide-ide yang dimiliki oleh siswa sebelum menerima suatu pembelajaran. Untuk menggali prakonsepsi siswa, peneliti menggunakan instrumen tes, yang terdiri dari 23 butir soal essay tentang kemagnetan, yang dikelompokan menjadi 7 kategori sub konsep.

Jawaban siswa dikelompokkan menjadi lima kategori, yaitu: 1) sesuai dengan pendapat ahli, 2) mendekati pendapat ahli, 3) sangat sedikit sesuai dengan pendapat ahli, 4) tidak sesuai dengan pendapat ahli, 5) tidak diisi sama sekali. Tabel 1 menunjukan persentasi prakonsepsi siswa

\section{Tabel 1. Persentase Rata Rata Tiap Konsep}

\begin{tabular}{lccccc}
\hline \multirow{1}{*}{ Kategori Konsep } & \multicolumn{5}{c}{ Persentase Rata Rata jawaban siswa } \\
& 1 & 2 & 3 & 4 & 5 \\
\hline Sifat Magnet & 18,9 & 10,5 & 12,6 & 24,2 & 33,7 \\
Pembuatan Magnet & 3,16 & 16,8 & 10,5 & 47,4 & 22,1 \\
Menghilangkan Kemagnetan & 0 & 10,5 & 15,8 & 42,1 & 31,6 \\
Membuat Rancangan Percobaan & 0 & 5,26 & 26,3 & 0 & 68,4 \\
Membuktikan Gaya Lorentz & & & & & \\
Medan Magnet Pada Solonoida & 0 & 0 & 0 & 31,6 & 68,4 \\
$\begin{array}{l}\text { Berarus Listrik } \\
\text { Medan Magnet Bumi }\end{array}$ & 0 & 0 & 0 & 34,2 & 65,8 \\
Teknologi Magnet & 0 & 0 & 1,75 & 26,9 & 71,3 \\
\hline
\end{tabular}

Tabel. 1 menunjukkan persentase rata-rata prakonsepsi yang dapat dijawab. Jawaban siswa kemudian dibandingkan dengan pendapat ahli. Nilai tertinggi dicapai siswa pada konsep sifat magnet, yaitu hanya sebesar 18,9\%. Nilai 
persentase tertinggi kedua adalah mengenai cara pembuatan magnet, yaitu sebesar $3,16 \%$. Untuk konsep magnet yang lainnya, siswa sama sekali belum mengenalnya, hal ini terlihat dari banyak lembar jawaban yang kosong. Sekitar 71,3\% siswa tidak menjawab soal-soal yang meminta penjelasan berkaitan dengan konsep teknologi magnet. Fakta yang terungkap bahwa pemahaman siswa mengenai konsep magnet serta penerapannya dalam teknologi sangat minim, sehingga perlu dimunculkan konteks teknologi kemagnetan dalam bahan ajar berbasis STEM untuk meningkatkan literasi sains dan teknologi siswa.

\section{Identifikasi Permasalahan Bahan Ajar IPA}

Tanggapan siswa mengenai bagaimana konsep-konsep IPA biasanya diajarkan sangat variatif. Hasil studi pendahuluan memperlihatkan persentase tanggapan yang rendah. Hasil tersebut diinterpretasikan sebagai respon negatif siswa, diantaranya terhadap: : (1) Pembelajaran yang membahas bagaimana sebuah alat teknologi bekerja $41,18 \%$ (2) Pembelajaran melalui kegiatan praktikum. 52,94\% (3) keterkaitan antara sains, teknologi, enjiniring, dan matematika. $54,50 \%$.

Hasil studi pendahuluan ini memberi petunjuk bahwa bahan ajar yang dikembangkan hendaknya memiliki kelebihan dari bahan ajar yang biasa digunakan. Salah satunya adalah bahan ajar berbasis STEM yang dapat membentuk siswa menjadi pemecah masalah, penemu, inovator, mampu mandiri, pemikir yang logis, serta melek sains dan teknologi (Morrison,2006).

\section{Penyusunan Bahan ajar}

Setelah menentukan tema, penyusunan bahan ajar dilanjutkan dengan mengumpulkan informasi dari artikel artikel elektronik, buku teks ataupun buku teknis yang membahas tema teknologi kemagnetan. Analisis wacana dilakukan pada artikel-artikel, dengan cara menyederhanakan bahasa, mengubah redaksi kalimat, dan menyeleksi informasi yang sesuai dengan KI, KD untuk siswa SMP.

Hasil akhir analisis wacana berupa teks luaran yang memiliki bahasa yang lebih sederhana. Penyusunan informasi dasar penting untuk dilakukan, dan akan digunakan sebagai kerangka bahan ajar. Konsep dasar yang telah disusun, kemudian diidentifikasi dan disesuaikan dengan kompetensi dasar bagi siswa SMP. Perumusan indikator literasi sains dan teknologi merupakan langkah selanjutnya yang dilakukan, agar mempermudah evaluasi setelah penerapan bahan ajar. Setelah informasi esensial tersusun, dilkukan perakitan bahan ajar, yang disesuaikan dengan urutan pembelajaran. Dalam merakit bahan ajar, terdapat proses penting yaitu:

a. Memperkaya pengetahuan yang relevan dengan konsep

Rekonstruksi bahan ajar tidak hanya menyederhanakan, tetapi juga dapat memperkaya dengan menyisipkan informasi-informasi tambahan yang memperkuat konsep yang dibahas (Duit et al., 2012). Salah satu contoh usaha memperkaya informasi dalam bahan ajar ini adalah tentang pergeseran kutub magnet bumi. Untuk meningkatkan kompetensi dalam mengubah bentuk satu data ke bentuk yang lain untuk memahami konsep inti teknologi, di dalam bahan ajar diberikan grafik pergerakan kutub magnet bumi di belahan bumi 
utara sejak tahun 1600. Data tersebut digunakan siswa menentukan jarak total dan kecepatan rata rata pergeseran kutub magnet dari tahun 1600 sampai tahun 2000, serta dapat memprediksi tampilan aurora yang berubah selama 100 tahun ke depan, yaitu kutub magnetik akan bergeser ke Siberia, dan bahwa aurora tidak akan lagi di atas Kanada sekitar tahun 2050, sehingga penampakan aurora akan jarang terlihat di Amerika Utara.

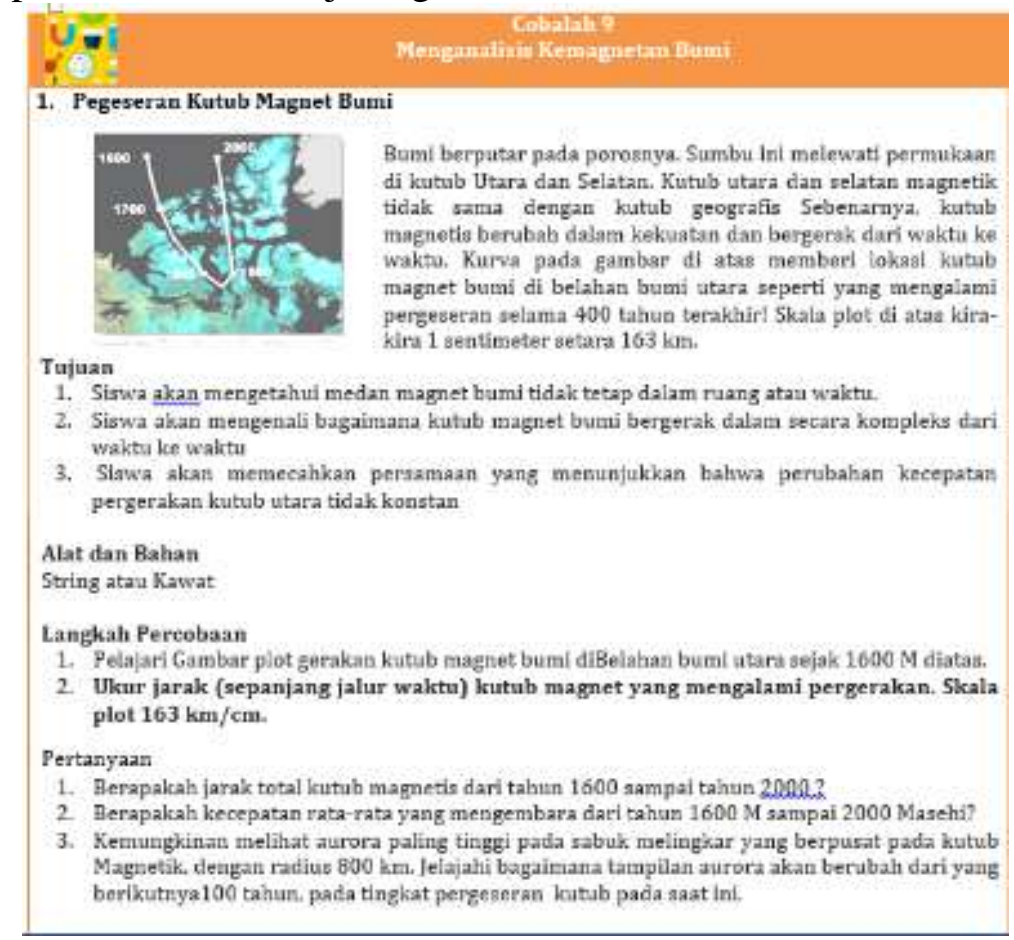

Gambar 2. LK untuk memperkaya pengetahuan magnet bumi

b. Menggunakan karakter kartun untuk menginformasikan pengetahuan yang penting.

Karakter kartun yang digunakan merupakan tokoh yang telah dikenal siswa. Dalam cerita fiksi, karakter tersebut memiliki kekuatan magnetik dan dapat mengendalikan logam. Melalui karakter tersebut, siswa diajak untuk memahami bahwa magnet dapat mempengaruhi semua objek yang ada di dunia. Magnet bisa mempengaruhi kayu, air, bahkan mengangkat tikus. Hal ini merupakan informasi baru bagi siswa, yang sebelumnya memahami bahwa magnet hanya bisa menarik besi.

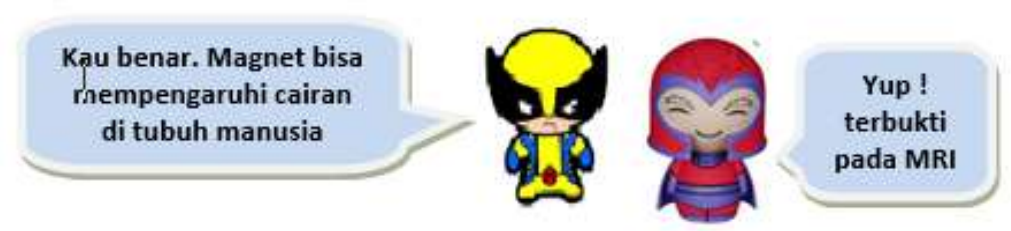

Gambar 3. karakter kartun yang telah dikenal siswa untuk menyampaikan informasi esensial 
c. Penyisipan Gambar

Selain membantu pemahaman siswa, gambar juga dapat memberikan tampilan yang lebih menarik terhadap bahan ajar. Gambar visual merupakan informasi yang lebih mudah diterima siswa dari pada informasi verbal. Informasi melalui gambar visual dapat bertahan dalam ingatan untuk waktu yang lebih lama, dibandingkan informasi verbal.

Menurut Cook (2008: 39-54), ilustrasi dalam bahan ajar dapat membantu siswa menyerap pengetahuan dan memahami konsep. Penyisipan gambar tentang teknologi pada MRI, Maglev, motor listrik, generator dan induktor ruhmkorf akan memperjelas dan memudahkan siswa untuk memahami cara kerja alat tersebut. Penyisipan gambar juga dilakukan dalam lembar kerja siswa, untuk membantu memperjelas rangkaian alat yang harus dibuat selama praktikum.

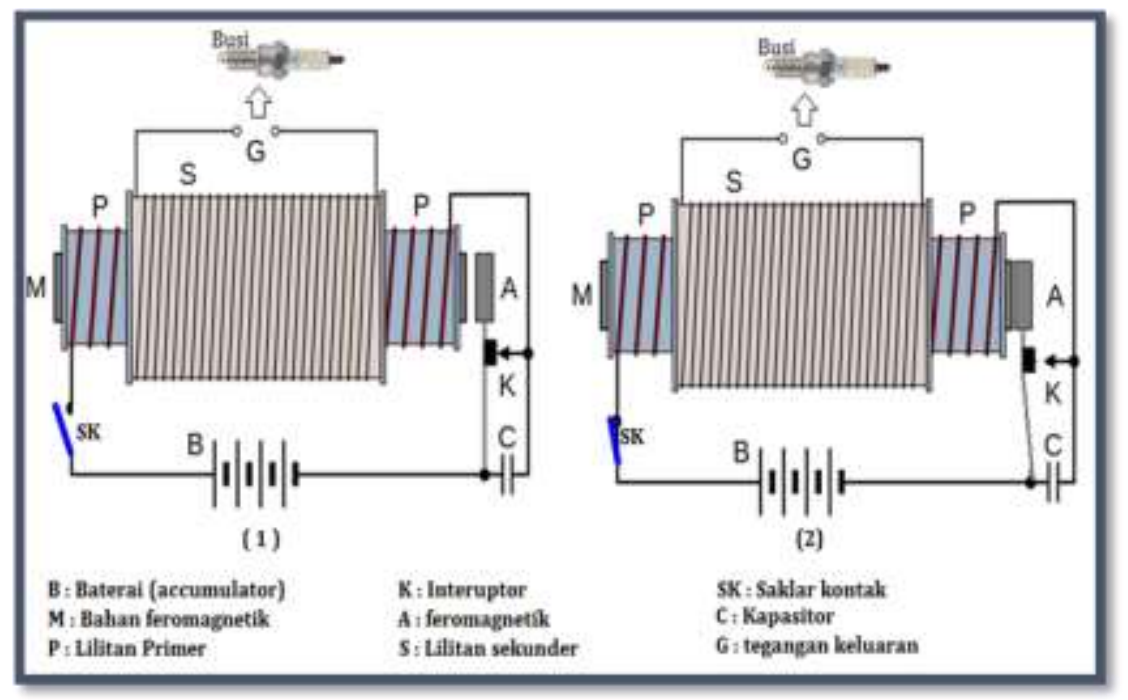

Gambar 4. Induktor Ruhmkorf

d. Soal literasi sains dan teknologi.

Unsur soal merupakan bagian yang sangat penting dari sebuah modul pembelajaran. Pada setiap sub bab pada modul ini, siswa difasilitasi dengan contoh soal, latihan soal dan evaluasi. Beberapa soal disusun berdasarkan konteks teknologi pada kehidupan sehari-hari. Contor soal dilengkapi dengan pembahasanya, sebagai bekal siswa untuk mengerjakan latihan soal.

\section{Merangkai Bahan Ajar Berbasis STEM}

Bahan ajar berbasis STEM yang dikembangkan, terdiri dari tiga bagian, yaitu pendahuluan, isi, dan penutup. Bagian pendahuluan terdiri dari Halaman Judul, Kata Pengantar, Daftar Isi, Peta Konsep, Kompetensi Dasar (KD), dan Tujuan Pembelajaran. Bagian isi terdiri dari lima sub tema. Bagian penutup terdiri dari Rangkuman Materi, Uji Kompetensi, Glosarium, dan Daftar Pustaka. 
Sains sebagai aspek paling utama diintegrasikan dalam bentuk pembahasan materi di setiap sub tema serta beberapa informasi terkait aplikasi konsep magnet.

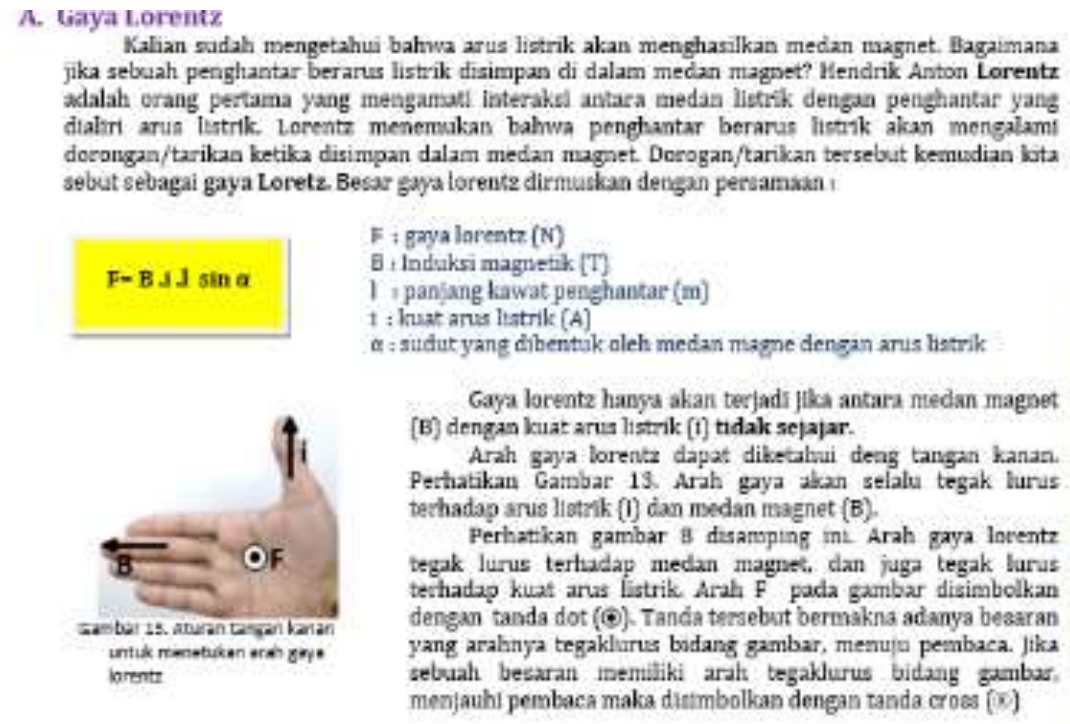

F ; gryalarentr $(\mathrm{N})$

B. laduksi magnetik [T]

1 i panjang kawat penghantar $(\mathrm{m})$

$1:$ kuar arus latrik $(A)$

$\alpha$ : audut yang dibentik aleh medan magne dengan arus hatrik

\begin{abstract}
(B) dengan kuat arua listrik (t) tidak sejajar.
Arah gaya lorentz dapat diketahui deng tangan kanas. Pethatikan Gatabar 13. Arah gaya atan selalu tegak hurus terhadag arus liatrik (1) dan medan magnet (B).

Perhatikan gambar 8 duamping int Arah gava locentz begak lirus terhadap medan magnet. dan jugz tegak larus teshadag kuat arus listrik. Arah F pada gambar disimbolkan dengan tanda dot (@). Tanda tersebut bermakna adanya beasran yang arabnya tegaklurus bodang gambar, menuju pembaca. Jika sebuah besaran inemitiki arats tegaklurus bidang sanbas menjauhi pernbaca maka dirtmbolkas dengan tanda croes (D)
\end{abstract}

Gaya lorentz hanya akan terjadi jlka antara medan magoet

Gambar 5. Fitur aspek sains pada konsep gaya Lorentz

Aspek teknologi diintegrasikan dalam bentuk pembahasan penerapan konsep dasar magnet yaitu Pensejajaran dipol magnet pada teknologi MRI dan interaksi kutub magnet berupa tarik menarik dan tolak menolak yang menjadi konsep dasar teknologi kereta Maglev.

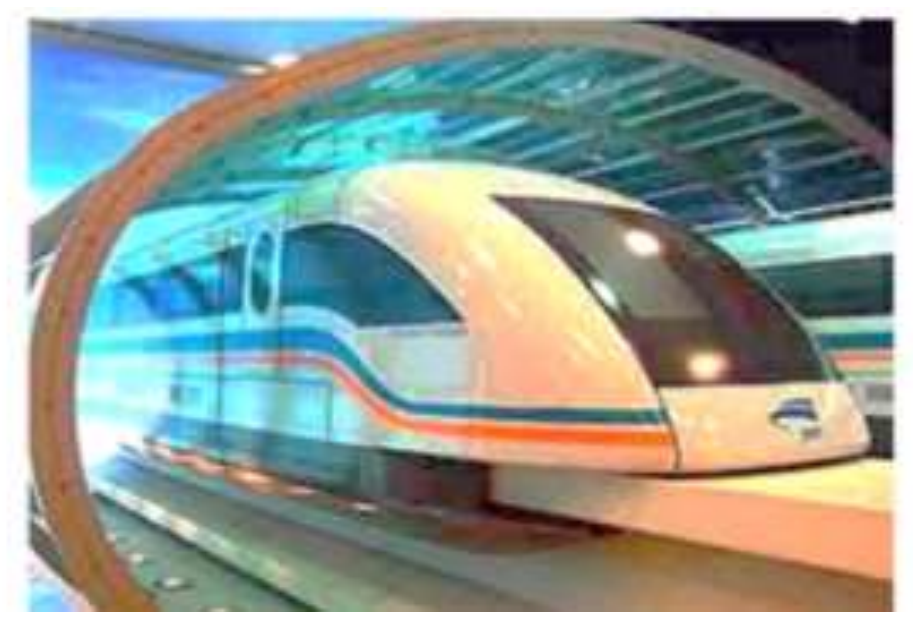

Gambar 6. fitur aspek teknologi Maglev pada bahan ajar

Aspek enjinering diintegrasikan dengan penguasaan sains yang telah didapatkan dalam bentuk kemampuan mendesain kompas, crane magnetic sederhana dan sebuah trafo. Sintaks yang digunakan dalam aspek engineering terdiri dari Define, Design, Operate dan Evaluate. Integrasi aspek enjinering ke 
dalam materi pembelajaran dapat membantu siswa mengembangkan penguasaan konsep dan kemampuan berpikir tingkat tinggi (Cantrell et al, 2006).

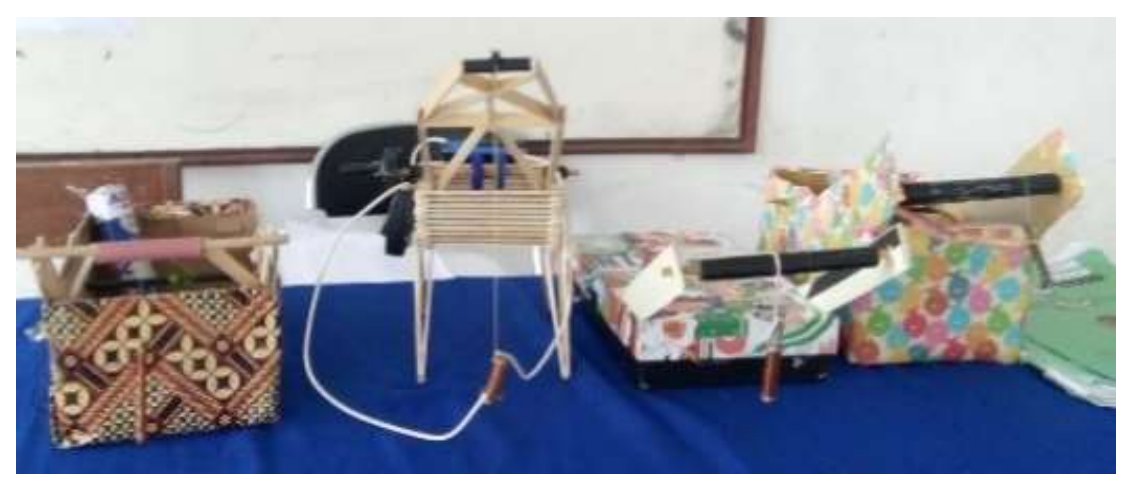

Gambar 7. Crane Magnetic sederhana hasil karya desain siswa. Unsur enjinering dalam bahan ajar STEM.

Aspek matematika di-integrasikan pada empat sub konsep dalam bentuk penggunaan lambang-lambang bilangan untuk penghitungan dan pengukuran. Hal tersebut dapat memudahkan pemahaman dan pemecahan masalah terkait dengan konsep fisika. Sesuai penelitian Andawiyah (2014: 69- 80), matematika dapat memudahkan memaknai sesuatu, sehingga mudah dipahami.

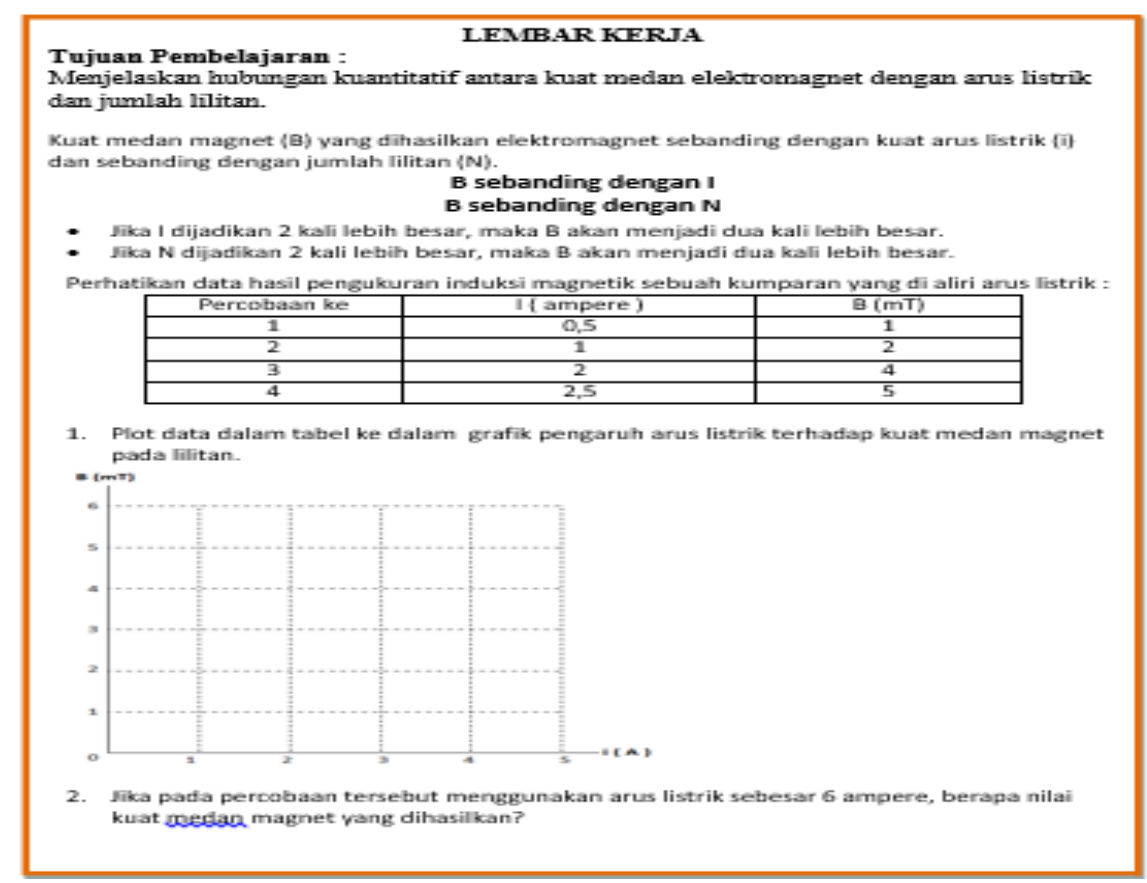

Gambar 8. mengubah data tabel menjadi grafik. Unsur matematika dalam bahan ajar STEM

\section{Validasi Materi Bahan Ajar}


Secara umum, aspek materi dinyatakan valid, meskipun terdapat beberapa catatan sebagai masukan untuk memperbaiki kekurarangan bahan ajar. Dalam menjelaskan konsep kemagnetan dilakukan melalui pemaparan materi dan melalui kegiatan praktikum. Satu orang validator masih menganggap kurang adanya kesesuian antara konsep kemagnetan dengan tema yang diusung yaitu teknologi magnet.

Tabel 2. Nilai CVI Pada Setiap Aspek Bahan Ajar.

\begin{tabular}{|c|c|}
\hline Aspek & Nilai CVR \\
\hline Materi & 0,88 \\
\hline Penyajian & 0,91 \\
\hline Bahasa dan Keterbacaan & 0,68 \\
\hline CVI & 0,82 \\
\hline
\end{tabular}

Penilaian bahan ajar keseluruhan meliputi aspek, 1) materi (konten dan konteks), 2) Penyajian, dan 3) Bahasa dan keterbacaan, Berdasarkan poin penilaian tersebut maka diperoleh CVR rata-rata untuk bahan ajar berbasis STEM adalah 0,82 . Untuk validator yang terdiri dari 20 orang, nilai minimal CVR yang diperlukan adalah 0,42 ( Lawshe, 1975). Nilai rata-rata untuk setiap aspek masih di atas nilai minimal CVR yang masih dapat diterima. $\mathrm{CVI}_{\mathrm{h}}>\mathrm{CVI}_{\mathrm{t}}(0,82>0,42)$ ini menunjukkan bahwa bahan ajar berbasis STEM yang dikembangkan layak digunakan.

\section{Efektivitas Bahan Ajar}

Efektivitas pembelajaran menggunakan bahan ajar berbasis STEM dilihat dari peningkatan literasi sains dan teknologi siswa, artinya bahan ajar berbasis STEM dapat dikatakan efektif digunakan dalam pembelajaran bila terjadi peningkatan literasi sains dan teknologi siswa.

Tabel 3. Persentasi nilai pretes dan postes

\begin{tabular}{lcccc}
\hline & \multicolumn{2}{c}{ Pretes } & \multicolumn{2}{c}{ Postes } \\
& skor & Persentase & Skor & Persentase \\
\hline Minimum & 4 & $16 \%$ & 14 & $56 \%$ \\
Maksimum & 11 & $44 \%$ & 23 & $92 \%$ \\
Rata-rata & 6,42 & $18,59 \%$ & 17,85 & $52,51 \%$ \\
Jumlah Siswa & \multicolumn{2}{c}{34} & \multicolumn{2}{c}{34} \\
\hline
\end{tabular}

Nilai $\% \mathrm{~N}$-gain dihitung dengan memasukan persentase nilai rata-rata postes (Sf) sebesar 52,51\% dan persentase nilai rata-rata pretes (Si) sebesar 18,59\%, dihasilkan nilai persentase $\mathrm{N}$-gain sebesar 41,47\%. Berdasarkan kriteria N-gain menurut Hake (1999), maka \% N-gain literasi sains dan teknologi siswa sebesar $41,47 \%$ termasuk kategori sedang. 


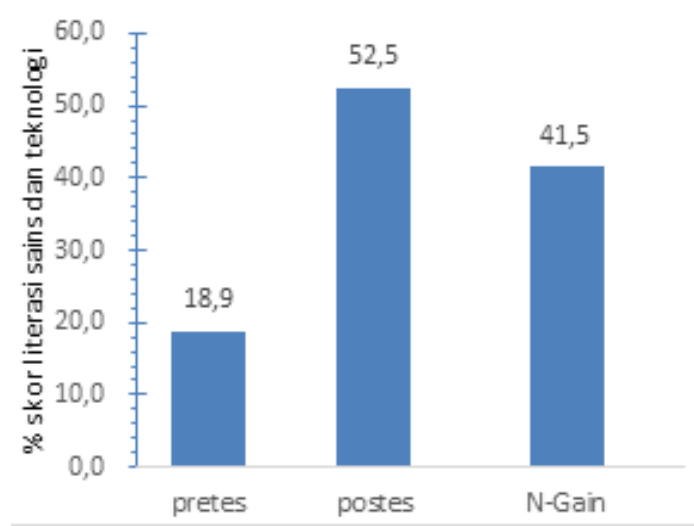

Gambar 9: Perbandingan persentase rata-rata pretes, rata-rata postes, dan N-gain kemampuan literasi sains dan teknologi siswa.

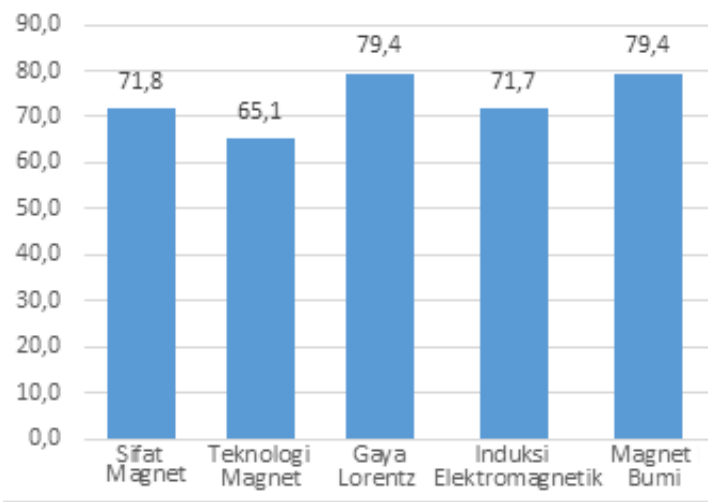

Gambar 10 : Perbandingan persentase rata- rata postes siswa per sub konsep.

Hasil terendah diperoleh pada sub konsep teknologi magnet, yaitu sebesar $65,1 \%$. Aktivitas pembelajaran pada sub konsep ini didominasi oleh pemaparan dengan bantuan gambar yang terdapat pada bahan ajar. Jika dibandingkan dengan sub konsep lainya, pembelajaran pada sub konsep teknologi maglev dan MRI dianggap sulit karena banyak istilah asing sehingga menyulitkan siswa dalam memahami sub konsep tersebut.

Hasil penelitian menunjukkan bahwa pembelajaran sains berbasis STEM dalam konteks teknologi kemagnetan sangat potensial meningkatkan literasi sains dan teknologi. Bell (2010) Literasi sains dan teknologi dapat mengembangkan keterampilan yang dibutuhkan di abad 21 seperti keterampilan teknologi, mahir berkomunikasi dan pemecahan masalah.

\section{KESIMPULAN}

Rekonstruksi bahan ajar berbasis STEM dengan model MER menghasilkan bahan ajar dengan karakteristik yang memuat konsep yang utuh dan kaya materi yang mendukung peningkatan literasi sains dan teknologi siswa. Hasil validasi terhadap bahan ajar berbasis STEM yang terdiri dari tiga aspek utama, yaitu aspek materi, 
aspek penyajian dan aspek bahasa dan keterbacaan. Nilai CVI bahan ajar pada tiap aspek menunjukkan bahwa setiap aspek pada bahan ajar valid dan dapat diterima. Bahan ajar berbasis STEM tidak hanya meningkatkan literasi sains dan teknologi s siswa, tetapi juga mendapatkan tanggapan positif dari siswa. Hal ini merupakan bukti bahwa bahan ajar berbasis STEM yang mengangkat tema kontekstual pada konsep-konsep IPA lainnya harus diupayakan.

\section{REFERENSI}

Andawiyah, R. 2014. Interrelasi Bahasa, Matematika dan Statistika. Okara Jurnal Bahasa dan Sastra, 8(2), 69-80.

Binkley, M., Erstad, O., Herman, J., Raizen, S., Ripley, M., Miller-Ricci, M., \& Rumble, M. (2012). Defining Twenty-First Century Skills. In P. Griffin, B. McGaw, \& E. Care (Eds.), Assessment and Teaching of 21st Century Skills. (pp. 17-66). Dordrecht: Springer.

Bybee, R. (2013), The case for STEM education: Challeges and Opportunity, NSTA press; Arlington, Virginia.

California Department of Education. 2015. Innovate: A Blueprint for Science, Technology, Engineering and Mathematics in California Public Education.

Cantrell, P., G. Pekcan, A. Itani, \& N. VelasquezBryant. 2006. The Effects of Engineering Modules on Student Learning in Middle School Science Classrooms. Journal of Engineering Education. 95(4): 301-309. Tersedia di http://onlinelibrary.wiley.com [diakses 19-4-2017].

Cook, M. 2008. Students' Comprehension of Science Concepts Depicted in Textbook Illustrations. Electronic Journal of Science Education. 12(1). 3954. Tersedia di http://ejse.southwestern.edu [diakses 22-5-2017]

Dikti. (2004). Bahan Ajar, [Online]. Tersedia:www.dikti.go.id/files/atur/KTSPSMK/11.ppt [16 Desember 2017]

Doppelt, Y. (2005). Assesment of Project Based Learning in a mechatronics context. Journal of Technology Education

Duit, R. (2007). "Science education research internationally: Conceptions, research methods, domains of research". Eurasia Journal of Mathematics, Science \& Technology Education. 3(1), 3-15.

Duit, R., Gropengieber, H., Kattmann, U., Komorek, M., Parchmann, I. (2012). The Model Of Educational Reconstruction - A Framework For Improving Teaching And Learning Sciences. Eurasia Journal of Mathematics, Science \& Technology Education. 5, 13-38.

Firman, H. (2015). Pendidikan sains berbasis STEM: Konsep, pengembangan, dan peranan riset pascasarjana. Disampaikan pada Seminar Nasional Pendidikan IPA dan PLKH Universitas Pakuan, Agustus 2015.

Hake, R.R., (1999). Analyzing Change/Gain Scores, [Online]. Tersedia: http://www.physics.indiana.edu/ sdi/AnalyzingChange-Gain.pdf

November 2017] 
Ismail, Permanasari, A. \& Setiawan, W. (2016). Efektivitas Virtual Lab Berbasis STEM dalam Meningkatkan Literasi Sains Siswa dengan Perbedaan Gender. Jurnal Inovasi Pendidikan IPA, 2 (2), 2016, 190 - 201

Ismunandar, Permanasari, A. (2004). Pedoman Penilaian Buku Pelajaran Kimia Sekolah Menengah Atas. Jakarta: Depdiknas

ITEA ( International Technology Education Association ). (2000). Standards For Technological Literacy: Content for The Study of Technology. Reston, Virginia : ITEA

Lawshe, C. H. (1975). “A Quantitative Approach to Content Validity”. Personnel Psychology. 28, 563-575.

Millah, E. S., Lukas S. B., \& Isnawati. 2012. Pengembangan Buku Ajar Materi Bioteklogi Di Kelas Xii SMA Ipiemssurabaya Berorientasi Sains, Teknologi, Lingkungan, Danmasyarakat (SETS). BioEdu. 1(1): 19—24.

Morrison, J. 2006. TIES STEM Education Monograph Series : Attributes of STEM Education. Baltimore, MD: TIES

Permanasari, A. 2016. STEM Education: Inovasi dalam Pembelajaran Sains. Prosiding Seminar Nasional Pendidikan Sains (SNPS) 2016

Poedjiadi, A. (2005). Sains Teknologi Masyarakat Model Pembelajaran Kontekstual Bermuatan Nilai. Bandung : Remaja Rosdakarya.

P21. 2008. 21st Century Skills, Education \& Competitiveness. Washington DC, Partnership for 21st Century Skills. P21. 2011. Framework for 21st Century Learning. Washington DC, Partnership for 21st Century

Puslitjaknov. (2008). Metode Penelitian Pengembangan, Jakarta: Depdiknas.

Ramdani, Y. (2012). "Pengembangan Instrumen Dan Bahan Ajar Untuk Meningkatkan Kemampuan Komunikasi, Penalaran, Dan Koneksi Matematis dalam Konsep Integral" Jurnal Penelitian Pendidikan. 13(1), 44-52.

Sanders, M. (2009). STEM, STEM Education, STEM mania. The Technology Teacher, hlm. 20-26.

Engineering Education Research ( J-PEER) 2(1):4

Syukri, H., Halim, L. \& Meerah, T. S. M. (2013).Pendidikan STEM Dalam Entrepreneurial Science Thinking "Escit”: Satu Perkongsian Pengalaman Dari UKM Untuk Aceh. Malaysia: Academy of Islamic Studies, University of Malaya, Kuala Lumpur.

Sulistyorini, H. (2006). Tingkat Keterbacaan Teks dan Pengaruhnya Terhadap Prestasi Belajar Siswa Pada Pokok Bahasan Larutan Penyangga di SMA Negeri Kramat Kabupaten Tegal. Skripsi Fakultas Matematika dan Ilmu Pengetahuan Alam. Universitas Negeri Semarang.

Wang, H. C., Hsu, C. W. (2006). Teaching-Material Design Center: An Ontology-Based System For Customizing Reusable E-Materials. 46( ) 458-470.

Wonacott, E. (2001). Technological Literacy (Vol. 233): ERIC Clearinghouse on Adult, Career, and Vocational Education. 